\title{
Novel 18650 Lithium-ion Battery Surrogate Cell Design with Anisotropic Thermophysical Properties for Studying Failure Events
}

Neil S. Spinner ${ }^{1,2}$, Katherine M. Hinnant ${ }^{1,3}$, Ryan Mazurick ${ }^{1,4}$, Andrew Brandon ${ }^{1,5}$, Susan L. RosePehrsson $^{1}$ and Steven G. Tuttle ${ }^{1, *}$

${ }^{1}$ U.S. Naval Research Laboratory

Navy Technology Center for Safety and Survivability

Chemistry Division

4555 Overlook Ave., SW

Washington, DC 20375

${ }^{2}$ National Research Council

The National Academies of Science

500 Fifth St., NW

Washington, DC 20001

${ }^{3}$ Nova Research, Inc.

1900 Elkin St., Suite 230

Alexandria, VA 22308

${ }^{4}$ Naval Research Enterprise Internship Program

Office of Naval Research

875 N Randolph St.

Arlington, VA 22217

${ }^{5}$ Assistant Professor

Department of Mathematical Sciences

Lycoming College

Williamsport, PA 17701

*Corresponding author, email: steven.tuttle@nrl.navy.mil; office: 202-767-0810;

fax: 202-767-1716 


\section{Introduction}

Due to several high profile and widely-publicized fire events over the past decade, fear and concern over the use of lithium-ion batteries in commercial and military products remains prevalent. Reports of incidents with batteries inside laptop computers [1], electric cars [2,3], and airplanes $[4,5]$ have elevated the level of unease amongst the masses despite the fact that lithium-ion battery fires are actually exceptionally rare, occurring in only around 1 out of every 1 to 10 million manufactured cells [6-8]. For electric vehicles (EVs) in particular, the frequency of fires is a slightly more sobering 1 out of 10 thousand; however, this still stacks up favorably compared with the rate of traditional gasoline-powered vehicle fires which has been reported to be about 1 in 1,300, or roughly 31 incidents per hour in the U.S. $[9,10]$. In light of these statistics, it seems evident that the primary concerns with respect to lithium-ion batteries result from a lack of knowledge and general fear of the unknown. It is therefore incumbent upon the scientific community to continue to thoroughly analyze and assess the risks associated with lithium-ion batteries to improve public awareness and maintain safety of commercial and military products.

Numerous studies have been conducted on various aspects of lithium-ion battery safety, abuse and failure testing, and thermal propagation from researchers at NASA [11,12], Sandia National Laboratories [13-15], and elsewhere [16-20]. Additionally, the U.S. Naval Research Laboratory (NRL) has been investigating lithium-ion battery safety through research focused on thermal runaway, failure, and cell-to-cell propagation in both single- and multi-cell battery packs [21-25]. In many of these tests, inert 18650-type surrogate cells containing no active materials were designed, fabricated and implemented to study the propagation of energy 
during failure events in multi-cell packs (only one active cell was used in each of these failure tests). Using surrogate cells in lieu of additional active lithium-ion batteries provided several key advantages to the testing: (i) increase in overall safety as only one active cell was subjected to a catastrophic failure/fire/explosion event per experiment, which also eliminated the risk of partially abused batteries that could undergo thermal runaway unexpectedly hours or even days after the initial test; (ii) decrease in cost by reusing surrogate cells from test to test and thereby reducing the number of fresh batteries needed to purchase; and (iii) the ability to monitor internal temperatures and radial distributions in real time without impractically and destructively interfering with an active cell by physically inserting thermocouples. Internal temperature monitoring and/or estimations are crucial since discrepancies of up to $40-50^{\circ} \mathrm{C}$ between the surface and internal temperatures of a battery can arise during an event, rendering simple surface temperature measurements inadequate for predicting accurate battery state of health $[19,26,27]$.

It should also be noted that the use of surrogate cells in place of active batteries prevents definitive determination of failure propagation. As an active battery undergoes failure and heats up nearby cells, additional failure events are likely to occur. Using non-active surrogate cells does not allow for subsequent failure events, making these experiments unsuitable for studying the effects of cell-to-cell propagation in a multi-cell lithium-ion battery pack. However, the ability to monitor internal temperature using surrogate cells provides extremely valuable insight, in addition to the other aforementioned benefits. This work focuses on leveraging these benefits to improve the understanding of heat transfer and temperature rise of lithium-ion batteries during catastrophic failure events. 
First-generation surrogate cells consisted of a standard nickel-plated steel 18650 cylindrical cell casing with a solid aluminum metal core. Aluminum was initially selected for its similar thermophysical properties to those of an active lithium-ion battery and its thermal stability to withstand failure conditions. However, there were two key issues associated with using aluminum. First, the thermal conductivity was roughly two to three orders of magnitude higher than an actual battery, resulting in identical internal temperatures regardless of radial position. This was undesirable since the "jelly roll" geometry of an active 18650 lithium-ion battery causes radial internal temperature gradients of around $5-15^{\circ} \mathrm{C}$, with even higher values possible during either rapid charging/discharging or strong convective heating/cooling [28-30]. Second, the solid cylinder of aluminum was unable to capture the anisotropic behavior of an active cell whereby heat transfer differs greatly between the axial and radial directions [30,31].

To improve upon the shortcomings of these original surrogate cells, a novel jelly rolltype design was implemented to more closely mimic the thermal behavior of an active 18650 lithium-ion battery. Thermophysical properties of these new surrogate cells were obtained via numerous techniques, and they were assembled into multi-cell packs to observe temperature distributions and heat transfer during a catastrophic lithium-ion battery failure event. From these results, we demonstrate a unique methodology for studying cell-to-cell failure that is cost effective, materials efficient, and dramatically safer than conventional techniques involving numerous active cells.

\section{Experimental}




\subsection{Surrogate Cell Design and Fabrication}

A jelly roll-type design was implemented using alternating layers of non-conductive mica (ultra high temperature, $0.61 \mathrm{~mm}$ thick) and stainless steel shim $(0.051 \mathrm{~mm}$ thick, $51 \mathrm{~mm}$ width) to mimic the internal construction of an active 18650 lithium-ion, which typically consists of layers of aluminum and copper electrodes separated by a non-conductive polymer separator (usually polyethylene and/or polypropylene) rolled into a cylinder. Figure 1 shows a photograph and diagram of the 18650 surrogate cell design. First, three small holes were punched into the bottom of an empty 18650 cell casing, and thermocouples (K-type) were inserted through each hole. Layers of mica and stainless steel were laid out flat and the three thermocouples were affixed to carefully selected locations. The entire assembly was then rolled as tightly as possible into a cylinder and stuffed into the empty casing. Fig. 1B shows the resulting locations of the three thermocouples after rolling: one in the center and two radially spaced at the edge of the jelly roll, but still inside the casing. The cell was then grooved (MSK500 Semi-Auto Grooving Machine, MTI Corp.), a cap was added, and it was finally crimped shut (MSK-510M Hydraulic Crimping Machine, MTI Corp.).

\subsection{Calorimetry}

To experimentally determine heat capacity, calorimetry tests were conducted with the 18650 surrogate cells, as well as with Teflon and aluminum (type 6061) to test the accuracy of the experimental method. About $900 \mathrm{~g}$ of deionized water was added to a thermally-insulated Dewar, and ice was stirred in incrementally until the water temperature was between $3-5^{\circ} \mathrm{C}$ 
without any residual floating ice. The final mass of water was then recorded. A stir bar was added, and the Dewar was placed onto a magnetic stir plate to provide constant stirring. Heating the object under study was carried out in one of two ways: either in a second, isolated beaker on a magnetic hot plate filled with deionized water and heated to around $80^{\circ} \mathrm{C}$ under constant stirring; or by placing the object inside a microclimate benchtop temperature test chamber at $120^{\circ} \mathrm{C}$ (Cincinnati Sub-Zero, MCB-1.2-.33-H/AC). All temperatures were monitored using K-type thermocouples. For the hot water bath heating tests, the object under study was completely submerged for at least 30 minutes to allow equilibration, followed by rapid transfer to the cold water bath. For the temperature chamber tests, the object under study was allowed at least 2 hours equilibration time, monitored via thermocouples, prior to quick transfer to the thermally-insulated Dewar. Inside the Dewar, the object was suspended completely into the water, rather than dropped to the bottom, to allow constant stirring and enable efficient heat transfer until the point of thermal equilibrium with the hot object and cold water bath.

A running 30-second temperature-time slope for the Dewar water bath, as well as a continuous average of the past 30 such slopes, were monitored. A similar analysis was performed independently for the Dewar by itself to determine the ambient temperature rise rate and pseudo-calorimeter constant for the temperature range between $5-8^{\circ} \mathrm{C}\left(5.13 \times 10^{-4}\right.$ ${ }^{\circ} \mathrm{C} / \mathrm{s}$ - see Supplementary Data, Figure S1). For all calorimetry experiments, the final water bath temperature was within this $5-8^{\circ} \mathrm{C}$ range, and thermal equilibrium was considered to be reached once the continuous averaged 30-second temperature-time slope dropped to below the ambient rise rate. Values for heat capacity were then calculated via a simple heat balance 
using the initial water and object temperatures, the final water temperature, and the masses of the object and water bath (see Supplementary Data).

Separate 18650 surrogate cells were fabricated for these calorimetry experiments since the original design contained three holes in the bottom for thermocouple wires that would allow intake of water and cause inaccurate measurements. These separate surrogate cells were fabricated with all the same internal components, but without punctured cell casings to prevent water intake. For each calorimetry test, four of these 18650 surrogate cells were tied together and used as a single object to increase the overall mass while confirming that the entire object could still be completely submerged beneath the cold water bath surface. Additionally, density was calculated by taking mass and volume measurements of these separately constructed, sealed 18650 surrogate cells, and the average density value for all fabricated surrogate cells was found to be $1593 \pm 30 \mathrm{~kg} / \mathrm{m}^{3}$ (uncertainty based on standard deviation).

\subsection{Axial Heating Method}

Axial thermal conductivity was obtained by combining insulated, directed heating experiments with an analytical solution to the time dependent, axial heat conduction equation, Equation 1:

$$
\frac{\rho C_{p}}{k_{z}} \frac{\partial \theta}{\partial t}=\frac{\partial^{2} \theta}{\partial z^{2}}
$$


where $\rho$ is the density, $C_{p}$ is the heat capacity, $k_{z}$ is the axial thermal conductivity, $\theta$ is the temperature rise from the initial value, $t$ is the time, and $z$ is the axial position. The associated boundary and initial conditions for these tests are shown in Equations 2-4:

$$
\begin{aligned}
& \left.\frac{\partial \theta}{\partial z}\right|_{z=0}=0 \\
& \left.\frac{\partial \theta}{\partial z}\right|_{z=H}=\frac{Q^{\prime \prime}}{k_{z}} \\
& \left.\theta\right|_{z, t=0}=0
\end{aligned}
$$

where $H$ is the 18650 cell length $(65 \mathrm{~mm})$ and $Q^{\prime \prime}$ is the applied heat flux. An analytical solution to Eq. 1, with boundary and initial conditions shown in Eq. 2-4 and assuming a constant Q", was proposed by Drake et al. and is shown in Equation 5 [30]:

$$
\theta(z, t)=\frac{Q^{\prime \prime}}{\rho C_{p} H} t+\frac{Q^{\prime \prime}}{2 k_{z} H}\left(z^{2}-\frac{H^{2}}{3}\right)+\sum_{n=1}^{\infty} \frac{(-1)^{n+1} 2 Q^{\prime \prime} H}{k_{z}(n \pi)^{2}} \cos \left(\frac{n \pi z}{H}\right) \exp \left(-\frac{k_{z}(n \pi)^{2}}{\rho C_{p} H^{2}} t\right)
$$

At long time lengths, the exponential term in the summation goes to zero, meaning the entire summation can be neglected. Eq. 5 can then be approximated as linear with respect to time (when $z$ is fixed), allowing $k_{z}$ to be estimated from the linear regression y-intercept of $\theta$ vs. $t$.

For the axial heating experiments, an 18650 surrogate cell was wrapped with electrically-insulating tape, and thermocouples were taped to the top and bottom circular surfaces. A commercial micro-foil heat flux sensor (RdF Corporation) was also affixed to the bottom surface in addition to the thermocouple. A circular piece of flexible copper foil was added to the bottom surface to evenly distribute the applied heat, and after another layer of 
insulating tape, nickel-chromium wire (AWG 22) was bent into a spiral pattern and attached on top of the copper foil. The entire assembly was then wrapped in fiberglass insulation, placed inside a vacuum chamber with feedthroughs for all attached instrumentation, and the air was vacuumed out to a gauge pressure of around $0.5 \mathrm{psi}$ to minimize convective heat loss. The Ni$\mathrm{Cr}$ wire was attached to a power supply, and the current was turned on to apply directed axial heating for a duration of 13 minutes per test with temperature and heat flux being actively monitored at the bottom $(z=H)$ of the cell and temperature at the top $(z=0)$. See Figure S2A in the Supplementary Data for a labeled diagram of the experimental setup.

\subsection{Radial Heating Method - Numerical}

The first technique for estimating radial thermal conductivity was via numerical analysis coupled with directed radial heating. This method was similar experimentally to the axial heating technique, but involved different analysis to extract the desired thermophysical property (in this case, radial thermal conductivity). An 18650 surrogate cell was again wrapped with insulating tape, and a thermocouple and micro-foil heat flux gauge were attached to the side of the cell casing. After a wrapping of flexible copper foil cylindrically around the cell (to evenly distribute applied heat) and another layer of tape, $\mathrm{Ni}-\mathrm{Cr}$ wire was wound spirally around the cell and connected to a power supply to provide directed radial heating. The assembly was then wrapped in fiberglass insulation, placed inside a vacuum chamber, and pumped down to a gauge pressure of about $0.5 \mathrm{psi}$. See Figure S2B in the Supplementary Data for a labeled 
diagram of the experimental setup. For each experiment, the power supply was turned on for the $\mathrm{Ni}-\mathrm{Cr}$ wire and heat was applied until the surface temperature reached $50^{\circ} \mathrm{C}$, at which point the current was shut off and the test was completed.

Numerical analysis was performed by applying a backwards Euler finite difference method to solve the time-dependent, radial heat conduction equation, Equation 6, with boundary and initial conditions stemming from the experimental setup shown in Equations 7-9:

$$
\begin{gathered}
\frac{\rho C_{p}}{k_{r}} \frac{\partial \theta}{\partial t}=\frac{1}{r} \frac{\partial}{\partial r}\left(r \frac{\partial \theta}{\partial r}\right) \\
\left.\frac{\partial \theta}{\partial r}\right|_{r=0}=0 \\
\left.\frac{\partial \theta}{\partial r}\right|_{r=R}=\frac{Q^{\prime \prime}}{k_{r}} \\
\left.\theta\right|_{r, t=0}=0
\end{gathered}
$$

where $k_{r}$ is the radial thermal conductivity, $r$ is the radial position and $R$ is the 18650 cell radius (9 mm). Solutions to Eq. 6 with conditions shown in Eq. 7-9 were obtained using the backwards Euler method with centered differencing on the spatial terms, and the secant method was then applied to minimize error between numerical solutions and the experimental data (for details on backward Euler and secant methods, see Supplementary Data). For each trial, a range of heat capacities, as well as the previously-measured value from calorimetry tests, were applied and the secant method was run for each $C_{p}$ until the error was minimized and a value for $k_{r}$ converged. An example of this procedure for a selected trial at a specific $C_{p}$ is illustrated graphically in Figure S3 (Supplementary Data). Finally, a global minimum with respect to error 
between solutions was identified and a respective error-minimized set of values for $C_{p}$ and $k_{r}$ were obtained for each trial.

\subsection{Radial Heating Method-Analytical}

A second method for estimating $k_{r}$ involved convective heat transfer coupled with an analytical solution to the time-dependent, radial heat conduction equation (Eq. 6). In a typical experiment, an 18650 surrogate cell was placed inside the microclimate benchtop temperature test chamber, and the chamber was set to an initial temperature $\left(T_{o}\right)$ and allowed approximately 2 hours to reach thermal equilibrium. A step change was then applied to a new temperature $\left(T_{\infty}\right)$ and the surrogate cell heated or cooled from $T_{o}$ to $T_{\infty}$ (depending on the direction of the step change) via convective heat transfer at the cell surface and radial propagation via thermal conduction. Temperature dependence for these experiments was assumed to be only in the radial direction due to the discrepancy in magnitudes between $k_{r}$ and $k_{z}[30]$, hence $r$ is the only independent spatial variable in Eq. 6 .

Based on the experimental conditions, the boundary and initial conditions for these radial convective heating experiments can be written as:

$$
\begin{aligned}
\left.\frac{\partial T}{\partial r}\right|_{r=0} & =0 \\
-\left.k_{r} \frac{\partial T}{\partial r}\right|_{r=R} & =h\left(\left.T\right|_{r=R}-T_{\infty}\right) \\
\left.T\right|_{t=0} & =T_{o} \quad \text { (for all } r \text { ) }
\end{aligned}
$$


where, in this case, $\theta$ is replaced with the temperature, $T$, and $h$ is the convective heat transfer coefficient. An analytical solution to Eq. 6 with conditions listed in Eq. 10-12 is shown in Equation 13 (proof can be found in Supporting Information of our previous paper [25]):

$$
T(r, t)=T_{\infty}+\frac{2\left(T_{o}-T_{\infty}\right)}{R} \sum_{n=1}^{\infty}\left(\frac{1}{\lambda_{n}}\right) \frac{J_{1}\left(\lambda_{n} R\right) J_{0}\left(\lambda_{n} r\right)}{J_{0}^{2}\left(\lambda_{n} R\right)+J_{1}^{2}\left(\lambda_{n} R\right)} e^{-\alpha \lambda_{n}^{2} t}
$$

where $J_{0}$ and $J_{1}$ are Bessel functions of the first kind of orders 0 and 1, respectively, $\alpha$ is the thermal diffusivity which is equivalent to $k_{r} / \rho C_{p}$, and $\lambda_{n}$ are the eigenvalues of the transcendental equation

$$
\lambda_{n} J_{1}\left(\lambda_{n} R\right)-\frac{h}{k_{r}} J_{0}\left(\lambda_{n} R\right)=0
$$

To determine an appropriate value for $h$ to use for calculations, the type of convection occurring inside the microclimate chamber needed to be identified. The chamber did not contain a mixing fan or blower; however, the cell was placed horizontally underneath a vent that provided some degree of air flow beyond that of simple free convection. The air speed from the vent at the cell location was measured using an Extech EN300 Hygro-ThermoAnemometer-Light-Sound Meter, and using three separate convection correlations an average value for $h$ of $35 \mathrm{~W} / \mathrm{m}^{2}-\mathrm{K}$ was calculated (see Supplementary Data for details). Since free convection values for $h$ are typically around $5-15 \mathrm{~W} / \mathrm{m}^{2}-\mathrm{K}$ and forced convection values are around $50-100 \mathrm{~W} / \mathrm{m}^{2}-\mathrm{K}[29,32]$, the value of $35 \mathrm{~W} / \mathrm{m}^{2}-\mathrm{K}$ indicated that the type of flow inside the chamber was somewhat of a median between free and forced convection, which was expected based on the characteristics of the air flow from the chamber vent. To obtain estimates of radial thermal conductivity, $C_{p}$ was fixed at either the previously-calculated value 
from calorimetry tests or the error-minimized value from radial numerical trials, and $k_{r}$ was repeatedly adjusted until the best fit between the analytical solution and experimental data was obtained. This best fit was considered to be when a minimum was reached using a least squares analysis (see Supplementary Data for further details).

\subsection{Battery Failure Tests}

Failure tests were conducted using the 18650 surrogate cells and active $18650 \mathrm{LiCoO}_{2}$ lithium-ion batteries (Tenergy, $3.7 \mathrm{~V}, 2600 \mathrm{mAh}$ ) to investigate both radial and axial heat propagation and temperature rise in the surrogate cells. Two different configurations of cell packages were designed and implemented (hexagonal and vertical), and Figure 2 shows labeled diagrams of both packages. Active cells were used as-received (approximately $30 \%$ state of charge) and brought to the point of thermal runaway and failure by overheating from an adjacent heater cell. This heater cell consisted of an aluminum core inside an 18650 cell casing with a large center hole bored out to accommodate a cartridge heater, which was then connected to a Variable Transformer (Staco Energy Products).

A repurposed $5 \mathrm{~m}^{3}$ two-man decompression chamber was used to safely conduct battery failure experiments. Custom modifications were performed on the chamber to enable remote control and monitoring of various functions, including chamber lights, power switches, exhaust and mixing fans, and a vent valve, as well as data collection from numerous devices and instrumentation, including thermocouples. Two reconfigurable embedded control and acquisition systems (CompactRIOs, National Instruments) used for controlling these chamber 
functions and collecting data were connected to a gigabit-enabled local area network (Gig-E LAN) and programmed using LabVIEW software (National Instruments) on a remote desktop computer. Two high speed cameras, one optical (HiSpec1, Fastec Imaging) and one infrared (SC6800, FLIR Systems), were also placed inside the chamber and into separate metal enclosures to protect against potentially harmful fluids expelled during battery failure. The enclosure for the optical high speed camera (HS) was fitted with a transparent soda lime glass window to allow imaging while remaining sealed, and the infrared camera (IR) enclosure was similarly fitted with a $2 \mathrm{~mm}$-thick ZnSe window (Edmund Optics) which was transparent to IR light. Both cameras were controlled by the remote computer and connected to it directly via $150 \mathrm{ft}$ Cat6 Ethernet cables to ensure high fidelity connections and prevent dropped frames. A $50 \mathrm{~mm}$ zoom lens (Nikkor f/1.2, Nikon) was attached to the HS camera, and both HS and IR cameras in their enclosures were mounted on lab jacks and adjusted to focus on the cell packages being tested. HS camera videos were acquired at a frame rate of $500 \mathrm{~Hz}$, and IR camera videos at a rate of $100 \mathrm{~Hz}$.

\section{Results and Discussion}

\subsection{Thermophysical Property Determination}

Stainless steel and mica were selected as materials for the 18650 surrogate cell internal jelly roll due to their stability at high temperatures (up to around $700^{\circ} \mathrm{C}$ for mica, around $1315^{\circ} \mathrm{C}$ for stainless steel), non-flammability, and ease to work with (i.e. bend, roll, and cut). Thermophysical properties for both materials are shown in Table 1. In addition, as illustrated in 
Table 1, mica possesses intrinsic anisotropy for in-plane (radial) vs. through-plane (axial) thermal conductivity, which is a characteristic of active 18650 lithium-ion batteries $[30,31,33]$. Therefore, these were promising materials for use in surrogate cells to accurately mimic the behavior of real cylindrical cells.

Calorimetry results for heat capacity, along with reported literature values, are shown in Table 2. Verification of the experimental method accuracy was carried out using materials with known values for $C_{p}$, aluminum and Teflon, and experimental results in Table 2 showed strong correlation to reported literature values. Calorimetry was then performed on 18650 surrogate cells, and Figure S4 (Supplementary Data) shows water bath temperatures and average temperature rise rates over time for a single trial with a vertical green dotted line indicating the time where the average temperature rise rate fell below the ambient calorimeter value $(5.13 \mathrm{x}$ $10^{-4} \mathrm{C} / \mathrm{s}$ ). The average heat capacity for the 18650 surrogate cells was found to be $727 \pm 18$, which was slightly below the range (less than 10\%) of typical literature values for $C_{p}$ of commercial lithium-ion batteries, and this was expected considering the individual heat capacities for mica and stainless steel as illustrated in Table 1. This surrogate cell heat capacity was also only around $19 \%$ lower than the value determined for a commercial $18650 \mathrm{LiCoO}_{2}$ battery in our previous study (896 $\pm 31 \mathrm{~J} / \mathrm{kg}-\mathrm{K}$ ) [25], demonstrating comparable thermophysical properties to an active cell.

Figure 3 shows experimental data for trials $1-5$ of the axial heating experiments, including temperatures at the top $(z=0)$ and bottom $(z=H)$ of the cell and applied heat flux vs. time (see Supplementary Data, Figure S5 for additional axial heating experimental data from trials 6-15). Linear regressions were performed for each temperature-time curve between 450 

range of average heat flux values across all trials were used to estimate $k_{z}$, and values were obtained from the linear regressions for both the top and bottom temperature-time curves for every trial. The average axial thermal conductivity from all trials for the 18650 surrogate cell was found to be $5.1 \pm 0.6 \mathrm{~W} / \mathrm{m}-\mathrm{K}$, which was somewhat low compared to most reported values, but still within the expected range seen in the literature of around $3-30 \mathrm{~W} / \mathrm{m}-\mathrm{K}[29-31,34]$. The relatively small axial thermal conductivity for mica $(4 \mathrm{~W} / \mathrm{m}-\mathrm{K})$ likely contributed to the depressed value for the 18650 surrogate cell since the majority of the internal jelly roll mass was mica, resulting from its sheet thickness that was over 10 times greater than the stainless steel.

Radial thermal conductivity, along with a second estimation of heat capacity, were obtained using a numerical analysis method with radial heating experiments. This technique provided a robust and accurate mechanism for determining $k_{r}$ and $C_{p}$, particularly due to its ability to account for the nonlinear, transient heat flux during the first couple minutes of each experiment (see Supplementary Data, Figure S6). Additionally, the applied heat was strictly in the radial direction, and thermally-insulated wrapping combined with the vacuum chamber effectively eliminated unwanted convective heat transport.

Results for the nine numerical analysis radial heating method trials, including steady state heat fluxes and global error-minimized values for $k_{r}$ and $C_{p}$ via the secant method, are listed in Table 3. Figure 4 illustrates graphically a series of error-minimized $k_{r}$ and $C_{p}$ values for a single trial, along with a green box indicating the set of global error-minimized parameters. For all nine trials, a range of heat capacities between $700-950 \mathrm{~J} / \mathrm{kg}-\mathrm{K}$ was selected to locate 
the global minimum error between solutions and because the expected heat capacity value was within this range. However, it was conceivable that additional minima could be found mathematically if the range of heat capacities were extended. Therefore, a $C_{p}$ range between $25-5000 \mathrm{~J} / \mathrm{kg}-\mathrm{K}$ was applied and examined numerically (see Supplementary Data, Figure S7 for graph with results from this extended $C_{p}$ range), and no additional minima were observed confirming the uniqueness of the results shown in Table 3.

The average $k_{r}$ and $C_{p}$ from the data in Table 3 were calculated to be $0.135 \pm 0.015$ $\mathrm{W} / \mathrm{m}-\mathrm{K}$ and $805 \pm 23 \mathrm{~J} / \mathrm{kg}-\mathrm{K}$, respectively. This second estimation of $C_{p}$ was within about $10 \%$ of the result obtained via calorimetry $(727 \pm 18 \mathrm{~J} / \mathrm{kg}-\mathrm{K})$, showing strong agreement between methods. In addition to the error-minimized values, a second set of numerical analyses was performed by fixing $C_{p}$ at the calorimetry-derived value and obtaining new results for $k_{r}$. These values are shown in Table 4, and the average radial thermal conductivity was calculated to be $0.197 \pm 0.019 \mathrm{~W} / \mathrm{m}-\mathrm{K}$. Both estimates for $k_{r}$ from the numerical analysis technique were slightly below the typical literature reported range, which is around $0.2-0.6 \mathrm{~W} / \mathrm{m}-\mathrm{K}[29-31,34,35]$, and lower than anticipated based on the radial thermal conductivities of the individual components. The reduced values for $k_{r}$ could likely be attributed to small air gaps in the surrogate cell jelly rolls since it was difficult to completely and perfectly pack the cell casings entirely with mica and stainless steel only, introducing small pockets of air which had a thermal conductivity over an order of magnitude below the jelly roll components [36].

The second method used for estimating $k_{r}$ was radial heating with an analytical solution (Eq. 13) to the time-dependent, radial heat conduction equation (Eq. 6). Figure 5 shows the best analytical fits for three temperature step changes at the center thermocouple location $(r=$ 
$0)$, while assuming the calorimetry-derived value for $C_{p}(727 \mathrm{~J} / \mathrm{kg}-\mathrm{K})$. The average $k_{r}$ from all three analytical fits shown in Fig. 5 was $0.120 \pm 0.033 \mathrm{~W} / \mathrm{m}-\mathrm{K}$. Similarly to the numerical analysis, this procedure was repeated using the average global error-minimized $C_{p}$ from the previous numerical technique $(805 \mathrm{~J} / \mathrm{kg}-\mathrm{K})$, and the results are illustrated graphically in Figure S8 (Supplementary Data). The average $k_{r}$ from all analytical fits in Fig. S8 was found to be 0.147 $\pm 0.041 \mathrm{~W} / \mathrm{m}-\mathrm{K}$. Similarly to the numerical method results, values for $k_{r}$ were somewhat lower than anticipated likely due to small air gaps in the jelly roll.

Relative uncertainties for $k_{r}$ estimates from the analytical technique $(\sim 28 \%)$ were significantly higher than for the numerical method ( 10\%), which likely arose from a couple assumptions associated with the analytical technique. First, at $t=0$ the chamber was assumed to be at $T_{\infty}$ when in reality it took a couple minutes, depending on the magnitude of the step change, for the chamber to fully reach $T_{\infty}$. Therefore, the heat flux at the cell surface, which was assumed to be constant based on Eq. 11, was not actually constant during the beginning of the experiment. Second, heat transfer was only considered in the radial direction to simplify the analytical solution, and while the cell was situated horizontally under the air vent, the top and bottom surfaces were not insulated to prevent some degree of axial heat transfer. These factors likely caused greater disparity amongst calculated values for $k_{r}$ with the analytical fit method, leading to greater overall uncertainties.

Figure 6 shows temperature vs. time curves, along with instantaneous temperature differences, for all three 18650 surrogate cell internal thermocouples during the three temperature step changes discussed in the aforementioned analytical radial heating experiments. Predictably, the largest magnitude step change (Fig. 6C) displayed the highest 
instantaneous radial temperature distributions $\left(7-9^{\circ} \mathrm{C}\right)$ due to a greater driving force for heat transfer, and the other step changes showed maximum radial distributions between about 4$6^{\circ} \mathrm{C}$. During a battery failure or aggressive heating event, the radial temperature distribution would likely be significantly higher $[19,26,27]$; however, the moderate temperature range (0$50^{\circ} \mathrm{C}$ ) and controlled nature of these surrogate cell tests were designed to illustrate typical behavior during normal operation of an active lithium-ion battery, where the radial temperature distribution is expected to be under $10^{\circ} \mathrm{C}$ [28]. Under typical operating conditions, it is therefore reasonable to assume, barring any abrupt temperature shifts or cell malfunctions, that the internal temperature of an 18650 lithium-ion battery is reasonably homogeneous.

A summary of all estimated 18650 surrogate cell thermophysical properties in this study, as well as typical literature reported values for commercial lithium-ion batteries, is shown in Table 5. Axial thermal conductivity was over an order of magnitude greater than radial thermal conductivity, highlighting the anticipated cell anisotropy, although values for both were slightly lower than those of an active battery. This may be attributed to small air gaps in the internal jelly roll components, as previously-mentioned, and also to the larger amount of mica present compared to stainless steel. Using either thicker stainless steel shim or more layers would likely increase both $k_{r}$ and $k_{z}$, but it could also decrease the value for $C_{p}$ based on the individual component thermophysical property values (Table 1). Since the value for $C_{p}$ was also found to be slightly lower than those of typical active batteries, a trade-off exists between the masses of stainless steel and mica to try and optimize surrogate cell values for $k_{z}$, $k_{r}$, and $C_{p}$. The 18650 surrogate cell configuration demonstrated herein was designed to 
attempt to provide balance amongst all thermophysical properties to mimic a real 18650 lithium-ion battery as accurately as possible.

\subsection{Battery Failure Experiments}

Despite relative homogeneity observed with surrogate cell internal temperatures during normal operation (Fig. 6), the situation changes dramatically when adjacent battery failure or another serious event takes place that provides rapid and extreme heat transfer. To investigate these effects in both the radial and axial directions, multi-cell packages were constructed, each containing a single active $\mathrm{LiCoO}_{2} 18650$ lithium-ion battery and several 18650 surrogate cells, and a catastrophic failure event was initiated via overheating. A hexagonal arrangement of cells (Fig. 2A) was produced to study radial heat transfer and temperature distributions, and a vertical configuration (Fig. 2B) was created to observe axial behavior.

HS and IR camera images, as well as temperature vs time curves and instantaneous surrogate cell internal temperature differences, for the hexagonal package are shown in Figure 7. The failure occurred in two stages: first, the battery briefly vented around the 21-minute mark which was slightly visible in the surrogate cell temperature curves shown in Fig. 7C-E, and clearly seen in the side-center temperature differences in Fig. 7F. After this initial venting, there was a brief decrease in the heating rate due to the expulsion of hot gases reducing the active battery mass and thermal energy for a short time. Finally, around the 26-minute mark the active cell underwent thermal runaway and ultimate failure, expelling hot gas, electrolyte, and smoke, resulting in a temperature spike before the surrogate heater cell was turned off. 
The active cell then finished its failure event and the entire package began to cool back to room temperature. Due to the low battery state of charge $(30 \%)$, no fire or sparking occurred during failure, and the maximum temperatures experienced by the surrounding surrogate cells were much lower than in previous experiments when dealing with severely overcharged and overheated batteries $[16,18,21]$.

Maximum surrogate cell temperatures during the failure event were unsurprisingly experienced by the 'A' position thermocouples, which were closest to the active cell and reached temperatures between $166-229^{\circ} \mathrm{C}$. The hottest cell was the one in position 5 due to its proximity to both the surrogate heater cell and the failing active cell. Temperature differences inside the surrogate cells shown in Fig. 7F confirmed the extreme radial distributions that can occur during a rapid heating event, with maximum differences between side and center thermocouples reaching as high as $43-71^{\circ} \mathrm{C}$ right at the point of failure.

Vertical package battery failure data is shown in Figure 8, including HS and IR camera images alongside surrogate cell internal temperatures and temperature differences vs. time. Once again, two venting stages occurred with smoke, gases and electrolyte being ejected without sparking or fire, however in this case the first venting caused the top surrogate cell to be expelled off the package (as shown in Fig. $8 \mathrm{~A}$ ). The bottom surrogate cell remained attached throughout the duration of the experiment, and exhibited a similar temperature-time curve as observed in Fig. $7 \mathrm{C}-\mathrm{E}$, although the maximum temperatures were much lower $\left(70-75^{\circ} \mathrm{C}\right)$. The majority of the energy released during both the initial venting and ultimate failure event was clearly in the vertical direction, so the bottom surrogate cell did not experience a dramatic a surge in heat transfer, although it should be noted that there was still a significant spike of 
about $20^{\circ} \mathrm{C}$ during the final failure event. For the top surrogate cell, maximum temperatures of $90-97^{\circ} \mathrm{C}$ were experienced during the initial venting which separated the cell from the package.

Instantaneous temperature differences in the top and bottom surrogate cells shown in Fig. $8 \mathrm{~F}$ reached maximums of around $10-12^{\circ} \mathrm{C}$. This result, compared with the result from the hexagonal package $\left(43-71^{\circ} \mathrm{C}\right)$, demonstrates experimentally the anisotropic thermal behavior of an 18650 lithium-ion battery and the disparity in magnitudes between $k_{r}$ and $k_{z}$. The jelly roll geometry which engendered a higher value for $k_{z}$ enabled facile axial heat transfer and greater uniformity of internal temperature, even during a catastrophic failure event and rapid surge of thermal energy, compared with the slower rate of radial heat transfer brought about by the smaller value of $k_{r}$. The maximum internal surrogate cell temperatures observed in all tests also indicated the extreme level of danger associated with battery failure in a multi-cell pack where cell-to-cell propagation may rapidly occur. These results show that a large temperature spike, combined with severe radial temperature distributions, could occur and lead to additional thermal runaway events depending on the proximity and orientation of cells in a large format lithium-ion battery pack.

\section{Conclusions}

A novel 18650 surrogate cell was designed and fabricated to accurately mimic the thermal behavior of an active 18650 lithium-ion battery. An internal jelly roll geometry was created to produce similar anisotropy found in real cylindrical batteries without the use of flammable or hazardous materials. These surrogate cells were probed via multiple techniques 
to determine thermophysical properties, including density, heat capacity, axial thermal conductivity and radial thermal conductivity, and all properties were found to be comparable to those of typical commercial lithium-ion batteries. As expected, axial thermal conductivity was found to be over an order of magnitude greater than radial thermal conductivity, although at moderate operating temperatures (up to $50^{\circ} \mathrm{C}$ ) only a minor radial temperature distribution was seen. This suggests that under normal operating conditions the internal temperature of an 18650 lithium-ion battery may be assumed to be relatively homogeneous.

Battery failure experiments were conducted using the 18650 surrogate cells alongside a single active $\mathrm{LiCoO}_{2}$ commercial 18650 lithium-ion battery, which was overheated to the point of total catastrophic failure. Internal temperatures were monitored leading up to, during, and after the point of battery failure for two distinct cell pack configurations: hexagonal and vertical. Instantaneous radial temperature distributions for hexagonal pack tests were as high as $43-71^{\circ} \mathrm{C}$, while for the vertical pack tests they only reached about $10-12^{\circ} \mathrm{C}$, demonstrating the anisotropy of thermal conductivity within the surrogate cell.

Thermophysical property determination combined with battery failure results illustrate the viability of these 18650 surrogate cells to accurately mimic active lithium-ion battery thermal behavior without the danger or expense of using active, flammable materials. For researchers looking to examine heat transfer and failure propagation in large format battery packs, these surrogate cells will enable a safe and cost effective alternative to using multiple active cells. 


\section{Acknowledgments}

The authors would like to thank the Office of Naval Research (award number 40001414WX20004) for financial support of this work. 


\section{References}

1. P. Hales, "Dell laptop explodes at Japanese conference." The Inquirer, June $21^{\text {st }}, 2006$. <http://www.theinquirer.net/inquirer/news/1042700/dell-laptop-explodes-japaneseconference>

2. B. Smith, "Chevrolet Volt Battery Incident Summary Report," NHTSA Report No. DOT HS 811 573, Office of Vehicle Safety Compliance, Washington DC, January 2012.

3. Associated Press, "New post-accident Chevy Volt engine fires prompt investigation." Fox News, November 25 ${ }^{\text {th }}$, 2011. <http://www.foxnews.com/leisure/2011/11/25/new-postaccident-chevy-volt-engine-fires-prompt-investigation/>

4. T. Kaiser, "Two more Boeing 787 Dreamliners catch fire, suffer technical issues." Daily

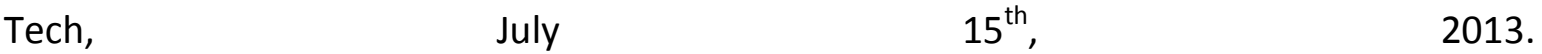
<http://www.dailytech.com/Two+More+Boeing+787+Dreamliners+Catch+ Fire+Suffer+\%20Technical+Issues/article31962.htm>

5. J. Ostrower, A. Pasztor, Y. Koh, "All Boeing Dreamliners are grounded world-wide." The Wall Street Journal, January $17^{\text {th }}$, 2013. <http://www.wsj.com/articles/ SB10001424127887323783704578246213461653662>

6. N.-S. Choi, Z. Chen, S.A. Freunberger, X. Ji, Y.-K. Sun, K. Amine, G. Yushin, L.F. Nazar, J. Cho, P.G. Bruce, Angew. Chem. Int. Ed. 51 (2012) 9994-10024.

7. Q. Wang, P. Ping, X. Zhao, G. Chu, J. Sun, C. Chen, J. Power Sources 208 (2012) 210-224.

8. J. Sherman, "Explosions? Electrocution? Fatal phone accidents are rarer than you think." Digital Trends, July $16^{\text {th }}$, 2013. <http://www.digitaltrends.com/mobile/explosionselectrocution-fatal-phone-accidents-are-rarer-than-you-think/>

9. "Why lithium batteries keep catching fire." The Economist, January $27^{\text {th }}, 2014$. <http://www.economist.com/blogs/economist-explains/2014/01/economist-explains-19>

10. M. Ahrens, "U.S. Vehicle Fire Trends and Patterns." National Fire Protection Association, Fire Analysis and Research Division, NFPA No. USS27, June 2010.

11. E. Darcy, J. Power Sources 174 (2007) 575-578.

12. K. Smith, G.-H. Kim, E. Darcy, A. Pesaran, Int. J. Energy Res. 34 (2010) 204-215.

13. J. Lamb, C.J. Orendorff, J. Power Sources 247 (2014) 189-196.

14. C.J. Orendorff, E.P. Roth, G. Nagasubramanian, J. Power Sources 196 (2011) 6554-6558.

15. C.J. Orendorff, J. Lamb, L.A.M. Steele, S.W. Spangler, "Propagation testing multi-cell batteries," Sandia Report, SAND2014-17053, August 2014.

16. Y. Fu, S. Lu, K. Li, C. Liu, X. Cheng, H. Zhang, J. Power Sources 273 (2015) 216-222.

17. W. Cai, H. Wang, H. Maleki, J. Howard, E. Lara-Curzio, J. Power Sources 196 (2011) 77797783. 
18. F. Larsson, B.-E. Mellander, J. Electrochem. Soc. 161 (2014) A1611-A1617.

19. R.A. Leising, M.J. Palazzo, E.S. Takeuchi, K.J. Takeuchi, J. Electrochem. Soc. 148 (2001) A838-A844.

20. Y. Liu, Q. Liu, Z. Li, Y. Ren, J. Xie, H. He, F. Xu, J. Electrochem. Soc. 161 (2014) A620-A632.

21. N.S. Spinner, C.R. Field, M.H. Hammond, B.A. Williams, K.M. Myers, A.L. Lubrano, S.L. Rose-Pehrsson, S.G. Tuttle, J. Power Sources 279 (2015) 713-721.

22. F.W. Williams, G.G. Back, "Lithium battery fire tests and mitigation," U.S. Naval Research Laboratory Formal Report, NRL/FR/6104-14-10,262, August 25 2014.

23. C.R. Field, M.H. Hammond, S.G. Tuttle, B.A. Williams, S.L. Rose-Pehrsson, N.S. Spinner, K.M. Myers, A.L. Lubrano, "Demonstration of experimental infrastructure for studying cell-to-cell failure propagation in lithium-ion batteries," U.S. Naval Research Laboratory Memorandum Report, NRL/MR/6180-14-9563, September 11 ${ }^{\text {th }}, 2014$.

24. N.S. Spinner, R. Ananth, S.G. Tuttle, S.L. Rose-Pehrsson, R. Mazurick, A. Brandon, "Lithium battery safety/cell-to-cell failure project FY14 progress report," U.S. Naval Research Laboratory Memorandum Report, NRL/MR/6180-15-9601, March 6 ${ }^{\text {th }}, 2015$.

25. N.S. Spinner, R. Mazurick, A. Brandon, S.L. Rose-Pehrsson, S.G. Tuttle, J. Electrochem. Soc. 162 (2015) A2789-A2795.

26. R. Srinivasan, B.G. Carkhuff, J. Power Sources 241 (2013) 560-566.

27. D. Belov, M.-H. Yang, Solid State lonics 179 (2008) 1816-1821.

28. G. Zhang, L. Cao, S. Ge, C.-Y. Wang, C.E. Shaffer, C.D. Rahn, J. Electrochem. Soc. 161 (2014) A1499-A1507.

29. S.-C. Chen, Y.-Y. Wang, C.-C. Wan, J. Electrochem. Soc. 153 (2006) A637-A648.

30. S.J. Drake, D.A. Wetz, J.K. Ostanek, S.P Miller, J.M. Heinzel, A. Jain, J. Power Sources 252 (2014) 298-304.

31. H. Maleki, S. Al Hallaj, J.R. Selman, R.B. Dinwiddie, H. Wang, J. Electrochem. Soc. 146 (1999) 947-954.

32. R.W. Serth, T.G. Lestina, "Process Heat Transfer: Principles, Applications and Rules of Thumb." Oxford, UK: Elsevier (2014).

33. A.S. Gray, C. Uher, J. Mater. Sci. 12 (1977) 959-965.

34. T.B. Bandhauer, S. Garimella, T.F. Fuller, J. Electrochem. Soc. 158 (2011) R1-R25.

35. E. Barsoukov, J.H. Jang, H. Lee, J. Power Sources 109 (2002) 313-320.

36. D.W. Green, R.H. Perry, "Perry's Chemical Engineers' Handbook, 8th Edition." New York: McGraw-Hill (2008).

37. T. Hirono, W. Tanikawa, Earth Planet. Sci. Lett. 307 (2011) 161-172.

38. L.P. Ogorodova, I.A. Kiseleva, L.V. Mel'chakova, T.N. Shuriga, Russ. J. Phys. Chem. A 82 (2008) 942-945. 
39. Metallic Materials Properties Development and Standardization (MMPDS-07). Battelle Memorial Institute (2012).

40. J. Blumm, A. Lindemann, M. Meyer, C. Strasser, Int. J. Thermophys. 31 (2010) 1919-1927.

41. G.T. Furukawa, R.E. McCoskey, G.J. King, J. Res. Natl. Bur. Stand. 49 (1952) 273-278.

42. M. Shadman Rad, D.L. Danilov, M. Baghalha, M. Kazemeini, P.H.L. Notten, Electrochim. Acta 102 (2013) 183-195.

43. A.A. Pesaran, M. Keyser, "Thermal characteristics of selected EV and HEV batteries." Annual Battery Conference: Advances and Applications, Long Beach, CA, 9-12 January 2001.

44. T.D. Hatchard, D.D. MacNeil, A. Basu, J.R. Dahn, J. Electrochem. Soc. 148 (2001) A755A761. 


\section{Figure Captions}

Figure 1. (A) Photograph and (B) diagram of novel 18650 surrogate cell.

Figure 2. Labeled diagrams of (A) hexagonal and (B) vertical packages of 18650 cells, including active cell (blue), heater cell (red and yellow), and surrogate cells (gray). (A) shows top view, while (B) shows a side view of the respective setups, and diagrams are not to scale. Cells were held together using insulating tape and gripped in place tightly during tests using a ring stand and clamp. Surrogate cells numbered sequentially, and positions for radially-spaced internal thermocouples labeled as ' $A$ ', ' $B$ ', and ' $C$ '.

Figure 3. Axial heating data for 18650 surrogate cell for trials 1-5 (see Supplementary Data, Figure S5 for trials 6-15 data). Solid lines (left axis) correspond to temperature rise at top ( $z=0$, bottom lines) and bottom ( $z=H$, top lines) of cell vs. time, and dotted lines (right axis) correspond to axially-applied heat flux vs. time. Voltage through $\mathrm{Ni}-\mathrm{Cr}$ wire was $1.3 \mathrm{~V}(\sim 0.90 \mathrm{~A})$.

Figure 4. Radial heating numerical analysis results for 18650 surrogate cell over a range of heat capacities from 700 - $950 \mathrm{~J} / \mathrm{kg}-\mathrm{K}$, as well as percent errors between experimental and numerical solutions. Data shown is from trial 3, and boxed in green is the global minimum corresponding to the lowest overall error and best approximation for thermal conductivity and heat capacity.

Figure 5. Radial heating data along with analytical fits for three temperature step changes for 18650 surrogate cell. Data acquired using microclimate benchtop temperature test chamber, and temperature vs. time curves all taken from center internal thermocouple $(r=0)$ with analytical fits derived using $C_{p}$ value from calorimetry data $(727 \mathrm{~J} / \mathrm{kg}-\mathrm{K}$ ) (see Supplementary Data, Figure $\mathrm{S} 8$ for additional data using error-minimized $C_{p}$ from numerical analysis data, 805 J/kg-K).

Figure 6. Step change temperature vs. time data for three internal thermocouples of 18650 surrogate cell inside microclimate benchtop temperature test chamber, as well as instantaneous temperature differences between side and center thermocouples vs. time. See Figure 1 for diagram of center and side thermocouple locations.

Figure 7. Hexagonal package battery failure results. (A) and (B) show HS and IR camera images of overheat failure event, respectively. (C), (D) and (E) show temperature vs. time curves from internal thermocouples of three separate 18650 surrogate cells (see Figure 2A for labeled diagram of cell locations) leading up to, during, and after failure event. (F) shows instantaneous temperature differences between center and side thermocouples during event. 
Figure 8. Vertical package battery failure results. (A) shows IR camera image of initial vent dislodging top surrogate cell, while (B) and (C) show HS and IR camera images of second, catastrophic failure event, respectively. (D) and (E) show temperature vs. time curves from three internal thermocouples from 18650 surrogate cells (see Figure 2B for labeled diagram of cell locations) throughout failure experiment. (F) shows instantaneous temperature differences between center and side thermocouples during event for top and bottom surrogate cells. 


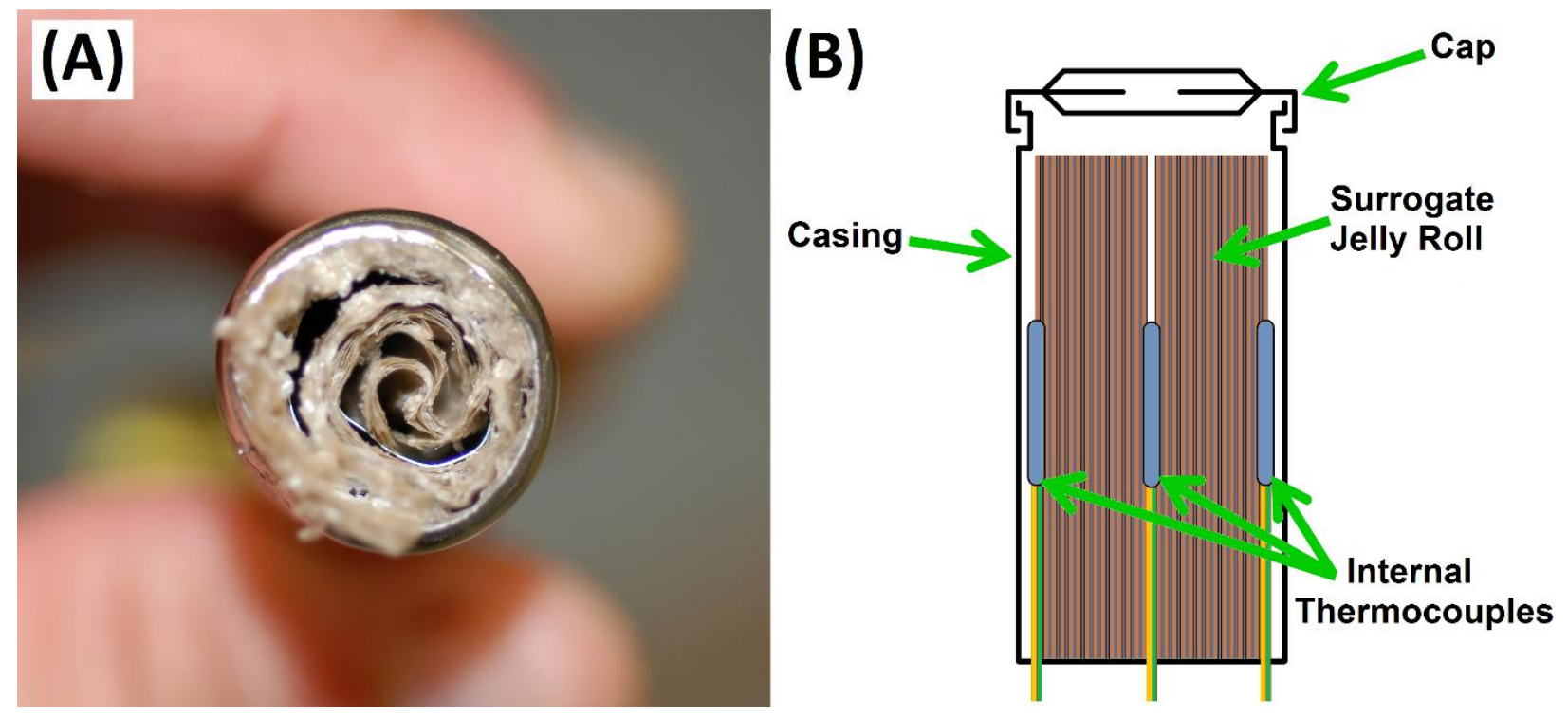

Figure 1 

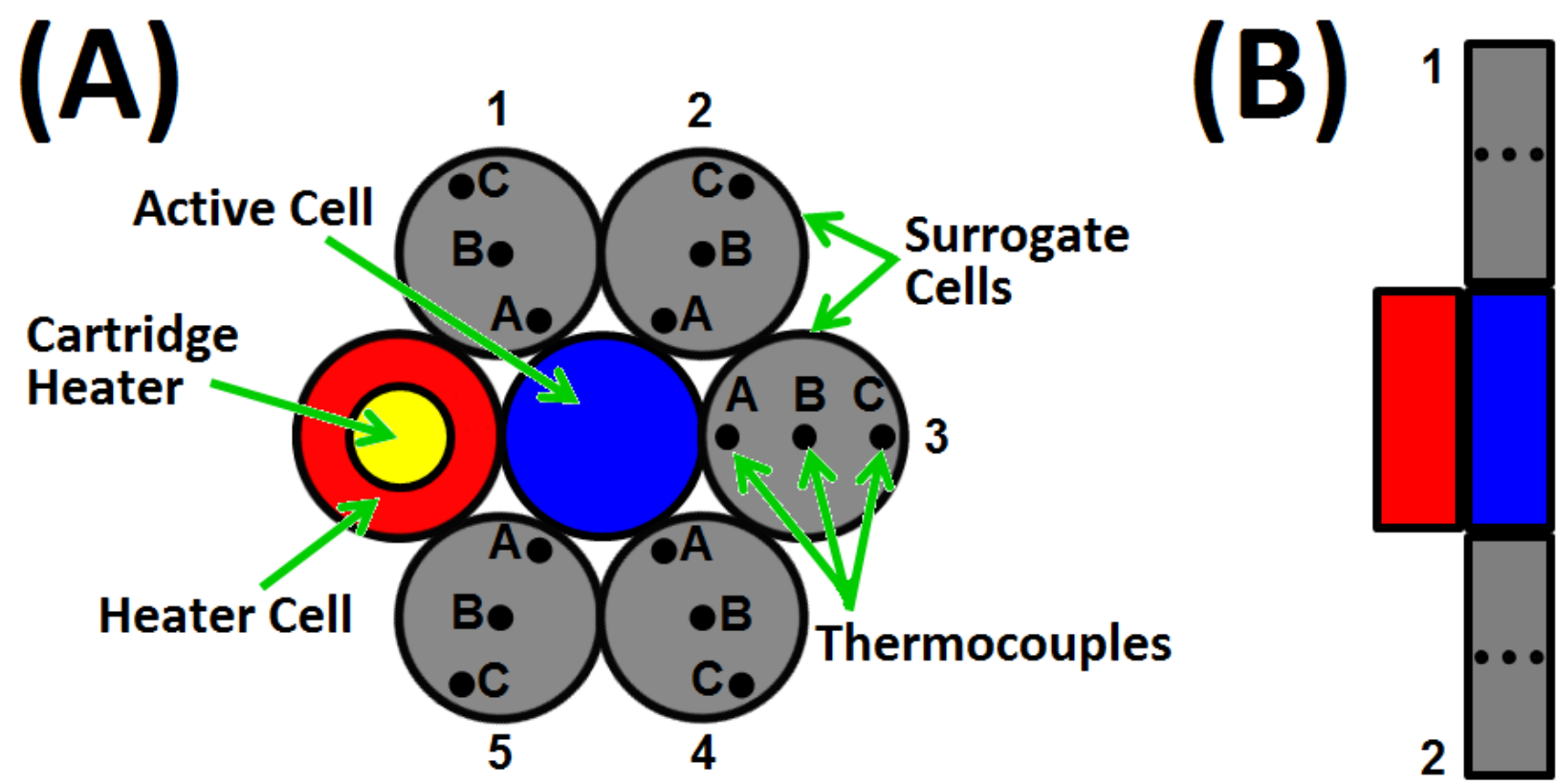

Figure 2 


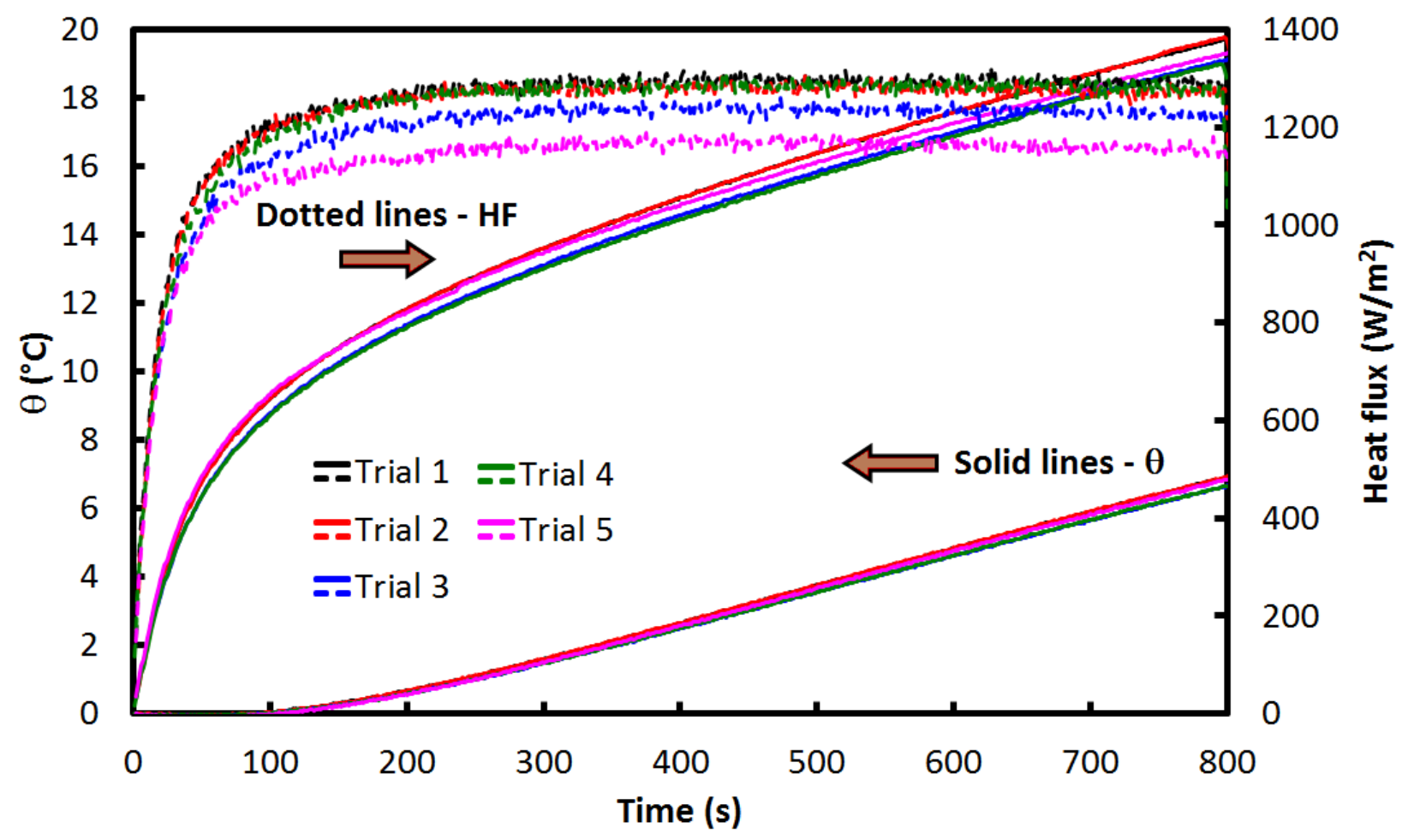

Figure 3 


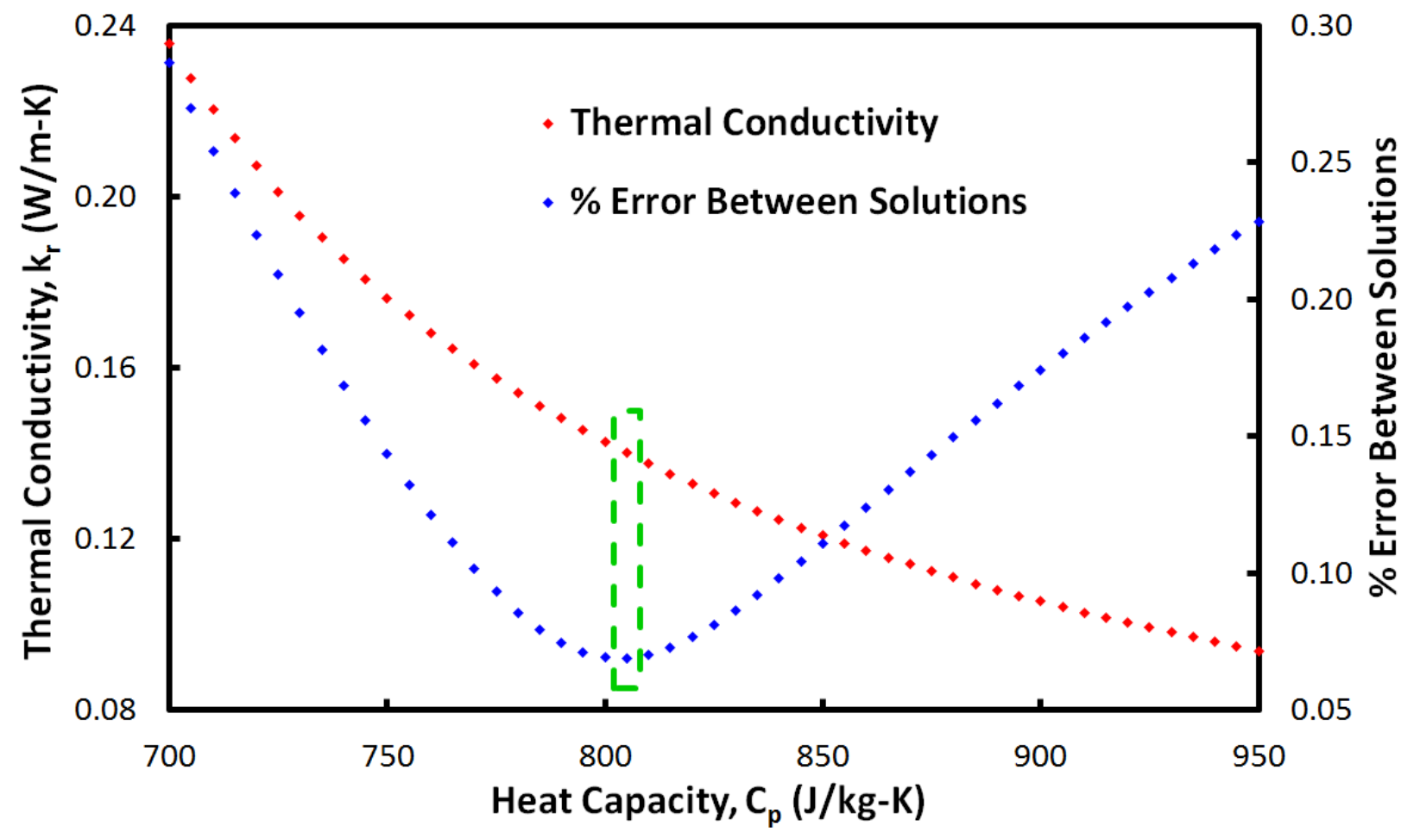

Figure 4 

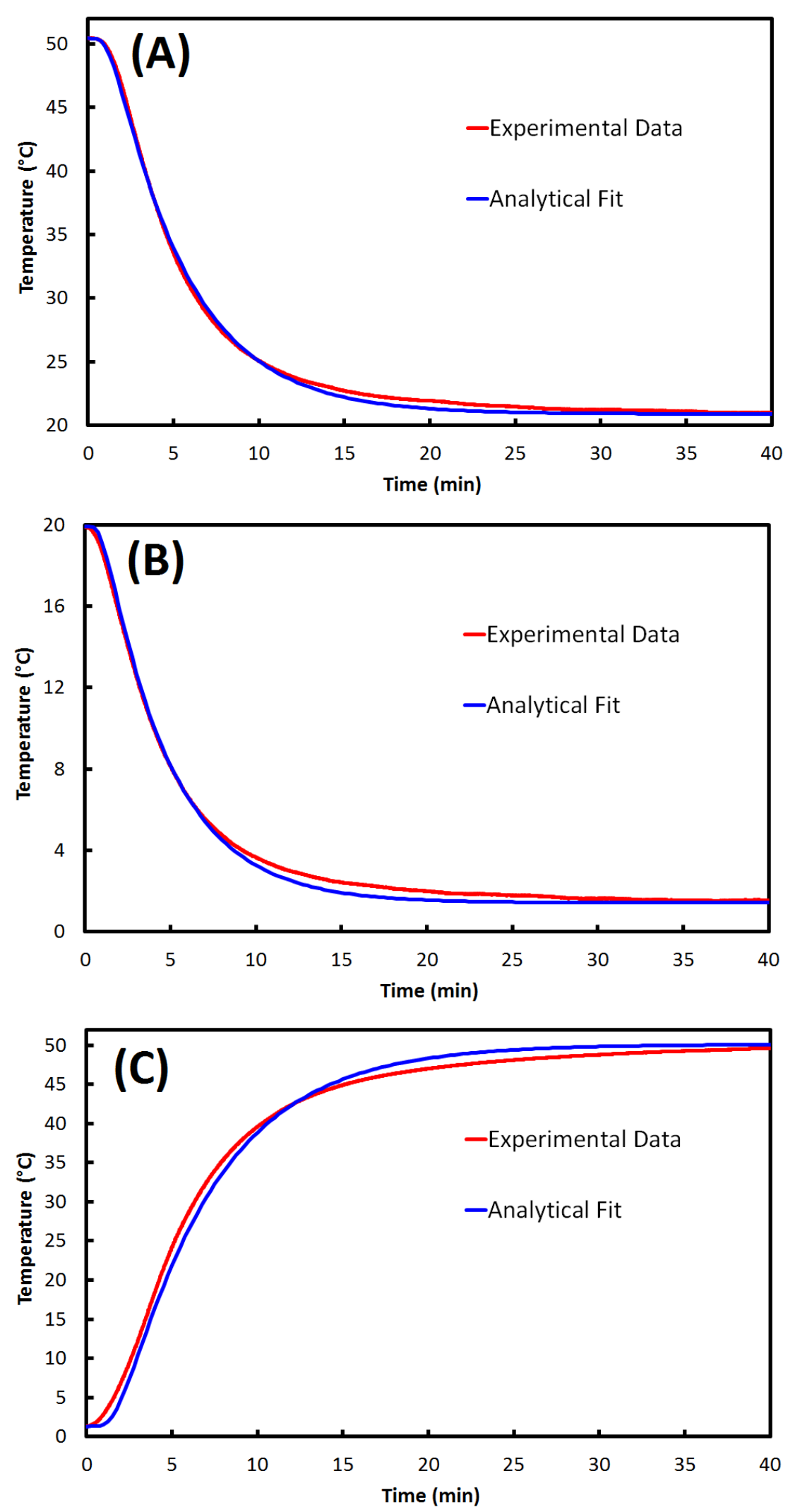

Figure 5 

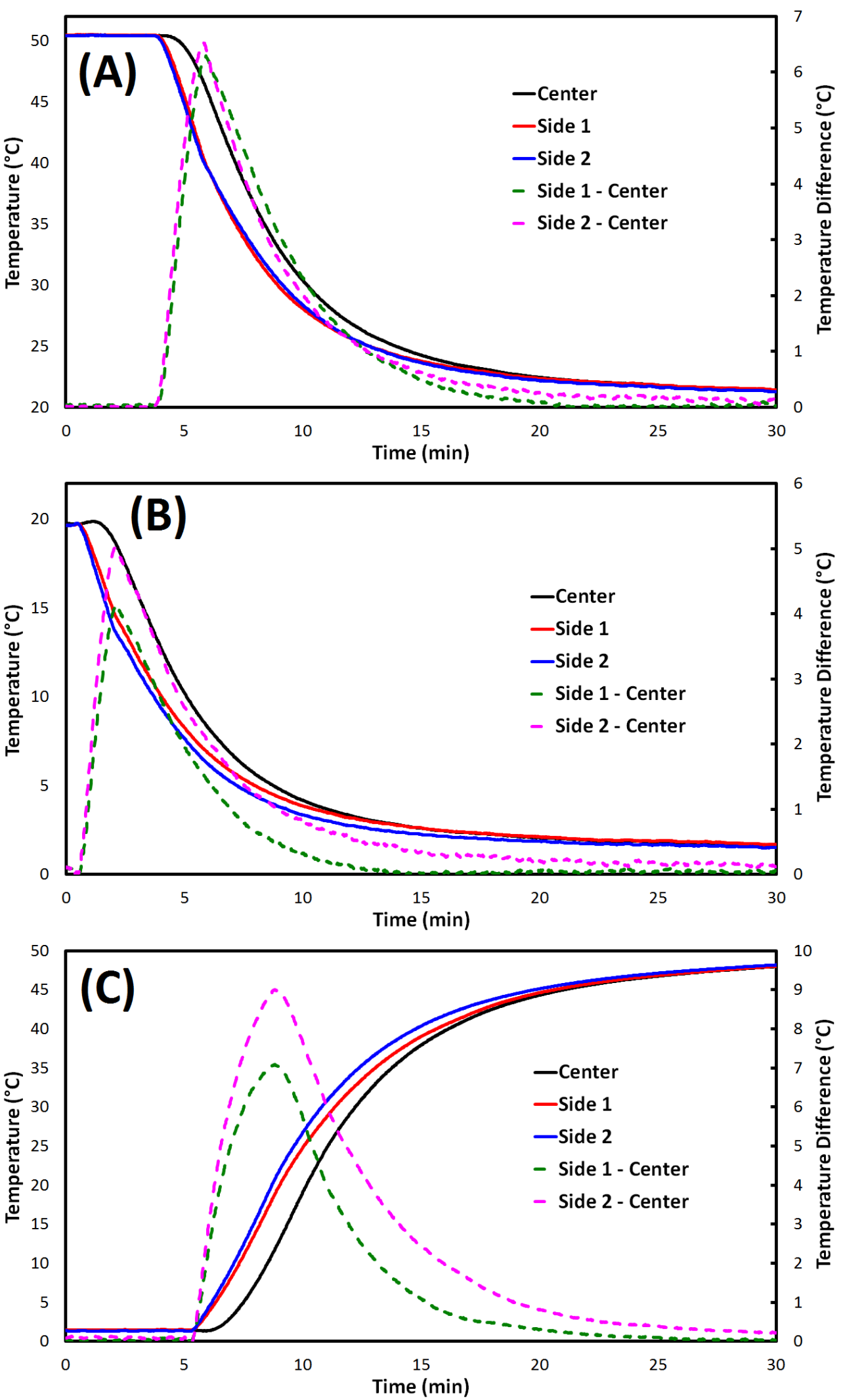

Figure 6 

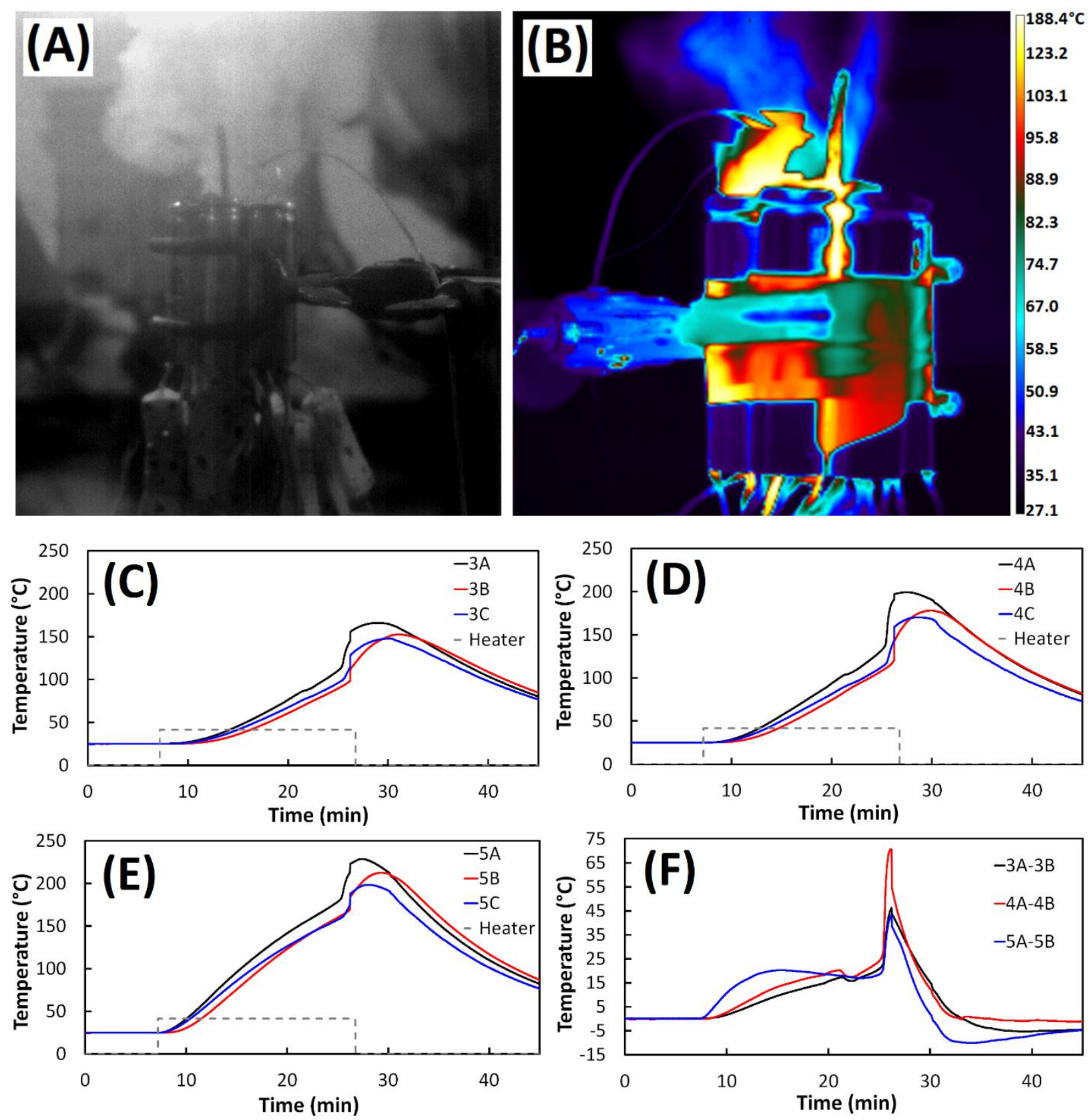

Figure 7 

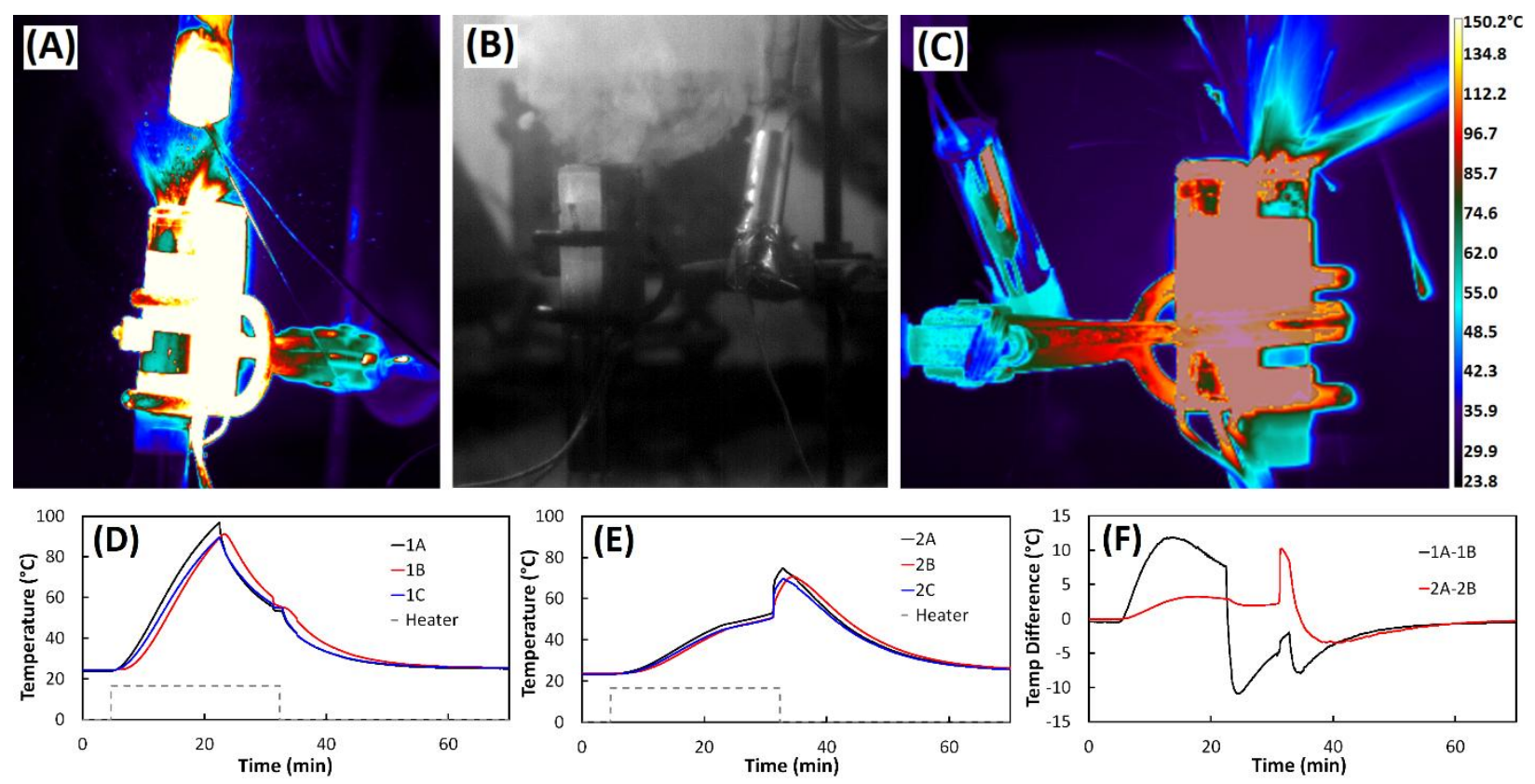

Figure 8 
Table 1. Values for heat capacity $\left(C_{p}\right)$, density $(\rho)$, and thermal conductivity $(k)$ of stainless steel and mica. Sources: $a-[33] ; b-[36] ; c-[37] ; d-[38]$; e-manufacturer's material specifications.

\begin{tabular}{|c|c|c|}
\hline & Stainless Steel & Mica \\
\hline $\mathbf{C}_{\mathbf{p}}(\mathrm{J} / \mathbf{k g}-\mathrm{K})$ & $500^{\mathrm{e}}$ & $800-820^{\mathrm{c}, \mathrm{d}}$ \\
\hline$\rho\left(\mathrm{kg} / \mathbf{m}^{\mathbf{3}}\right)$ & $8030^{\mathrm{e}}$ & $2900^{\mathrm{b}, \mathrm{c}}$ \\
\hline $\mathbf{k}(\mathbf{W} / \mathbf{m}-\mathbf{K})$ & $16.2^{\mathrm{e}}$ & $\begin{array}{c}0.45 \text { (radial) }^{\mathrm{a}, \mathrm{b}} \\
4 \text { (axial) }^{\mathrm{a}}\end{array}$ \\
\hline
\end{tabular}


Table 2. Heat capacity values obtained from calorimetry tests for aluminum (type 6061), Teflon, and 18650 surrogate cells, along with reported literature values for aluminum, Teflon, and commercial lithium-ion batteries. Sources: $a-[30]$; b- [31]; c- [34]; d- [35]; e - [36]; f- [39];

\begin{tabular}{|c|c|c|c|c|}
\hline & \multicolumn{4}{|c|}{$\mathrm{C}_{\mathrm{p}}(\mathrm{J} / \mathrm{kg}-\mathrm{K})$} \\
\cline { 2 - 5 } & Aluminum & Teflon & $\begin{array}{c}\mathbf{1 8 6 5 0} \\
\text { Surrogate Cell }\end{array}$ & $\begin{array}{c}\text { Commercial Li-ion } \\
\text { Batteries }\end{array}$ \\
\hline Calorimetry & $860 \pm 8$ & $1073 \pm 17$ & $727 \pm 18$ & --- \\
\hline Literature & $860-890^{\mathrm{e}, \mathrm{f}}$ & $1000-1200^{\mathrm{g}, \mathrm{h}}$ & --- & $800-1700^{\mathrm{a}, \mathrm{b}, \mathrm{c}, \mathrm{d}, \mathrm{i}, \mathrm{j}, \mathrm{k}}$ \\
\hline
\end{tabular}

$\mathrm{g}-[40] ; \mathrm{h}-[41] ; \mathrm{i}-[42] ; \mathrm{j}-[43] ; \mathrm{k}-[44]$. 
Table 3. Summary of data from nine radial heating numerical analysis tests for 18650 surrogate cells.

\begin{tabular}{|c|c|c|c|}
\hline Trial & $\begin{array}{c}\text { Steady State Heat } \\
\text { Flux }\left(\mathbf{W} / \mathbf{m}^{2}\right)\end{array}$ & $\mathbf{k}_{\mathbf{r}}(\mathbf{W} / \mathbf{m}-\mathbf{K})$ & $\mathbf{C}_{\mathbf{p}}(\mathrm{J} / \mathbf{k g}-\mathrm{K})$ \\
\hline 1 & 270 & 0.133 & 795 \\
\hline 2 & 272 & 0.136 & 820 \\
\hline 3 & 276 & 0.140 & 805 \\
\hline 4 & 188 & 0.110 & 825 \\
\hline 5 & 187 & 0.120 & 830 \\
\hline 6 & 187 & 0.118 & 835 \\
\hline 7 & 359 & 0.153 & 770 \\
\hline 8 & 364 & 0.157 & 795 \\
\hline 9 & 370 & 0.143 & 770 \\
\hline
\end{tabular}


Table 4. Radial thermal conductivity values for 18650 surrogate cell from radial heating numerical analysis tests using calorimetry-derived heat capacity value (727 J/kg-K).

\begin{tabular}{|c|c|}
\hline Trial & $\mathbf{k}_{\mathbf{r}}(\mathrm{W} / \mathrm{m}-\mathrm{K})$ \\
\hline 1 & 0.180 \\
\hline 2 & 0.210 \\
\hline 3 & 0.199 \\
\hline 4 & 0.190 \\
\hline 5 & 0.225 \\
\hline 6 & 0.219 \\
\hline 7 & 0.178 \\
\hline 8 & 0.202 \\
\hline 9 & 0.166 \\
\hline
\end{tabular}


Table 5. Summary of 18650 surrogate cell thermophysical properties estimated from various techniques, as well as typical properties of commercial lithium-ion batteries reported in the literature. For radial heating thermal conductivity values, a) corresponds with the errorminimized heat capacity (805 J/kg-K), and b) corresponds with calorimetry-derived heat capacity value (727 J/kg-K). Sources: $a-[29] ; b-[30] ; c-[31] ; d-[34] ; e-[35] ; f-[43]$.

\begin{tabular}{|c|c|c|c|c|c|}
\hline & Calorimetry & Axial Heating & $\begin{array}{l}\text { Radial Heating } \\
\text { - Analytical }\end{array}$ & $\begin{array}{l}\text { Radial Heating } \\
\text { - Numerical }\end{array}$ & $\begin{array}{c}\text { Commercial Li-ion } \\
\text { Batteries }\end{array}$ \\
\hline$C_{p}(J / k g-K)$ & $727 \pm 18$ & --- & --- & $805 \pm 23$ & $800-1700^{b, c, d, e, f}$ \\
\hline$k(W / m-K)$ & --- & $5.1 \pm 0.6$ & $\begin{array}{l}\text { a) } 0.147 \pm 0.041 \\
\text { b) } 0.120 \pm 0.033\end{array}$ & $\begin{array}{l}\text { a) } 0.135 \pm 0.015 \\
\text { b) } 0.197 \pm 0.019\end{array}$ & $\begin{array}{l}0.2-0.6 \text { (radial) }^{a, b, c, d, d, e} \\
\text { 3-30 (axial) }{ }^{a, b, c, d}\end{array}$ \\
\hline
\end{tabular}

